\title{
The Problems and Countermeasures of Animal Protection in Zoos--Take Shenyang Glacier Zoo for Example
}

\author{
Bingbing Cui \& Dezhong Jiang \\ Shenyang University, No. 21 Wanghua South Street, Dadong District \\ Shenyang 110044, China \\ E-mail: bingb-ndb@163.com
}

\begin{abstract}
With the continuous expansion of the scale of the zoo, living environment of animals is deteriorating. Taking the problems appeared in Glacier Zoo in Shenyang as example, the author analyzed the reasons for the phenomenon and put forward corresponding countermeasures such as establishing animal protectors association and fund and carrying out education for the protection et. al.

Once defined as zoo with four functions including the education of science popularization, scientific research, animal reproduction protection and leisure and recreation, the establishment of them is to protect animals better so that several species which are in weak positions or rare endangered get better protection and long-term development. Meanwhile, it also can enhance people's understanding for animals' habits so as to promote the communications between human beings and animals and provide materials for animal science research so as to promote the education of science popularization and cultivate people's love. But with the increase of zoos and continuous expansion of its scale, the phenomena which the animals in zoos are abused appear constantly and become severe day by day and the living environment of animals is deteriorating. The article takes the problems appeared in Glacier Zoo in Shenyang as example to analyze the reasons for the phenomena and put forward corresponding countermeasures.
\end{abstract}

Keywords: Zoo, Protection, Animals

\section{The current status of animal protection in zoos}

The phenomena northeast tigers in Glacier Zoo in Shenyang kill their species such that three adult northeast tigers killed another one happened in recent years. According to the analysis of experts, it is most likely caused by food undersupply since winter. Shenyang Glacier zoo grew out of Wanquan Park, which renamed its name as Shenyang zoo in 1979 and is the only one zoo in Shenyang, and from which at least two generations in Shenyang recognized wild animals. In 2000, the zoo moved to Shenyang Qipan Mountain forest \& wild animal Park which covers an area of $3600 \mathrm{mu}$ and was restructured into a private enterprise so as to become the largest zoo in the Northeast. After being removed to the new location the zoo constructed a stocking area coving 150 million square meters and the killed northeast tiger by his species was found in the stocking area. In November 2009, because of poor management the zoo once was shut down so that the monkeys was too hungry to eat the weeds on the earth and the everyday rations of elephants was just a pile of straw. The manager of the park said, the total cost of feed, electric power of all kinds of supporting facility, water supply and workers' wages which used for feeding more than 2 thousand animals was about 20 thousand, but there were only about ten persons to show around the park and each entrance ticket was 80 Yuan so the income was a mere drop in the bucket. Finally the local government lent 1 million to the zoo so that it was over the hump temporarily. But in 2010, eleven northeast tigers died off in three months in Shenyang forest \& wild animal Park, which caused the attention of all circles. People questioned the voice that northeast tigers which were rare and endangered species of our country died off. According to the report provided by the zoo for wild animal protection management station of Shenyang Forest Bureau, from November 112009 to February 27 2010, eleven northeast tigers died of pulmonary abscess, heart failure, hemorrhagic enteritis, nephritis, renal failure, myocarditis et al respectively. But people approved the tigers died of long-term high malnutrition which also meant they died of hungry. Another 20 tigers were in the edge of life and death. Anytime there will be new tigers which die of malnutrition. The remained 55 kinds of more than 500 animals including 20 tigers in the zoo are in the condition that nobody are feeding and attending to them. 


\section{The existing problems of animal protection in zoos}

\subsection{The reasons the living environment of animals in zoos is deteriorating}

Many private zoos massively appeared for seeking economic profits, but the private management didn't change animal living environment. On the contrary, it made animals become the markets' victim. Once there is problem in the process that marketers manages zoos, their direct reaction is to reduce the cost. The main parts of operating cost in zoos is animal the feeds and maintenance so animals' normal life cannot be guaranteed so that the phenomena appeared they died even killed their species. Meanwhile, the reasons for the phenomena that northeast tigers killed their species in Shenyang Glacier zoo also include that the unsound construction and the operating system of the zoo as well as the low quality of managers in the zoo.

\subsection{To seek economic profits in the name of environmental protection}

Many zoos reproduced animals in large numbers in the name of protecting wild animal species but in fact they used them for dealing with other wild animal parks but not for protecting and expanding species. What's more, some zoos sold directly their animals to circus for performing and taking photos to carry on naked money transaction. At present animal performance mainly included birds, marine mammals, elephants, beast and primates et. al and there were a lot of difficult and dangerous programs against animal nature such as upper air wire walking, riding motorcycle to wire walking, high-altitude sliding, jumping through a hoop and playing pokers et. al. Wild animals are afraid of fired naturally but they have to perform in the force of trainers. Many animals move back instinctively before jumping through a hoop but the trainers drive with whip and club while no zoo provides safety protection equipment for animals. In addition, in order to secure the tourists' safety while they ride to take photos, almost all the zoos carry on mutilation such as removing teeth, cracking nails for the tigers and loins used for taking photos which leads the fatality rate is much higher than ordinary animals.

\subsection{The low quality of Managers}

Spreading knowledge and love should be the true value of zoos' existence. People go to zoos to want to know animals and their habits, enlarge their views, obtain skills of getting along with animals and accept the education and edification of animal protection. In Germany, in order that the children are not violent, taking good care of small animals is the first class of kind-hearted education many young children accept. But it is a pity that some managers of zoos think the phenomena such as animal performance, extracting teeth from animals et. al are not mistreatment and the so called hit and beat the visitors see are the misunderstandings of animal breeds. In fact they seek economic profit at the expense of being against animal nature from their own views. But animals live in the world like the human beings and they should enjoy their own rights to exist. So it cannot be denied that the deeds which deprive other species' existence rights to achieve self-interest is mistreatment substantially. From management point of view, Showing animals' living habits normally before visitors is what people want to see really so how to return their own ways of living to animals should be the problems that managers of zoos should consider really.

\subsection{The construction and operation of zoos lack legislation}

At present in fact wild animal park in our country is a vacuum without legal hindrance and it remains the state of self-discipline. In 1988 the Law of the People's Republic of China on the Protection of Wild Animals adopted by our country identifies wild animal legal position but there is no legal position for running, experimental and entertainment animals et. al. There is no corresponding penalties regulation for the deeds that animals are abused. But in other countries, this kind of legislation and enforcement go ahead such as Indian tiger constitution, American tortoise passport and punishment because of catching birds, United Kingdom's bat law and so on and many places are worth us using for reference.

\subsection{Unclear administration department}

The main enforcement agency of "the Law of the Protection of Wild Animals" is national forestry department but the management of zoos and circus is under the control of different government sectors and their management department is very unclear. Therefore once the problems appear it is impossible to find corresponding department to solve the problems in time. National forestry bureau only takes charge of the ownership of wild animals but it is restricted to approval of wild animal import and there is no positive management department for the management of wild animal Park.

\section{Countermeasures}

There are still a lot of problems to solve in the aspect of our country's zoos' management now. We should take effective countermeasures from the respects of administrative guidance, legislative restriction and individual 
obeying law.

\subsection{Advocate scientific ecological ethical moral values}

We should firmly reject Naturalism and Extreme Human Center Theory and reshape the thought of harmonious coexistence between man and nature among environmental morality, ecology ethics and nature rights. Humans should respect, protect and make use of nature reasonably, coordinate the relationship between humans and nature, and strengthen the ecological ethical moral concept of the harmony between social productive forces and natural productive forces, the harmony between economic re-production and natural re-production, the harmony between economic system and ecological system, the harmony between humanized nature and non-humanized nature and the harmonious coexistence between man and nature.

\subsection{Hold to scientific protection and progress view and rationally develop and utilize wild animal resource}

We should emphasize both protection and utilization. It is necessary to enhance balance and harmony between man and nature so that people can work and live in a sound and beautiful ecological environment. To remain the implementation of continuous development strategy, we should deal with the relationship between economic development and population, resources, environment, improve ecological environment and beautifying living environment, and improve public facilities and perfecting social welfare facilities. We should strive to find a civilized road to develop higher productivity, rich life and sound ecosystem. We should deal with the dialectical relations among protection, development and utilization correctly, adhere to rational perspectives on development and rationally develop and utilize wild animal resource.

\subsection{Improve the quality of zoo managers and practitioners}

From the view of management, state government agencies and departments should be involved into management and they pay more attentions and provide help for the management of zoos from broad and strategic views. Firstly, they should raise the management level, strengthen management, optimize the hardware facilities in the park, enhance and improve animals' eating, sleeping and sanitary conditions while they formulate a series of corresponding regulations on administration aiming to the visitors and take the work of consulting and managing visitors and tourists as the key points; Secondly, the relationship between zoos' managers and breeders and animals is most intimate so their deeds are most influential on animals and it is necessary to provide regular training for them. First of all, to make them know about animal characteristics, animal self-value and their value for humans et. al to cultivate their love. Only there is love in their mind they are shown in their work. Meanwhile it is necessary to carry on regular assessment for them and establish perfect including practitioners' pre-post training system. We advise to provide room for memorialization such as cemetery and monument for the animals which were abused to death so that the visitors feel the condolences to the died animals and generate strong touch to enhance the consciousness of cherishing animals. At the same time some animal parks also could establish sustainable development education bases in order to ask the students communities to show around, which not only improve students' cognition for animal protection but also promote the zoos to create income and increase animal maintenance fees.

\subsection{Establish animal protectors association and fund}

To set up animal protection fund plays a very important role in animal protection. Meanwhile it can provide financial support for the zoos which devote themselves to animal protection but have not been state sponsored. Appropriately narrowing the capital gap between state and private animals so as to avoid zoos' bankruptcy because of capital problems can also improve the operating confidence of private zoos so that they treat the animals in the zoos better. For the zoos which could not last indeed, firstly, they should deal with the things such as the animals' transferring, stocking and the aftermath. For the excellent managers and breeders they should arrange appropriately their works. In society, there may be animal protection volunteers association who will explain voluntarily the contents such as all kinds of animals' habits to the visitors and tourists. At the same zoos' managers will also learn good feedbacks and suggestions which are from society and can enrich animal environment from the volunteers. Of course, zoos also should restrict visitors' behaviors and discourage their uncivilized behaviors.

\subsection{Carry out the education of protection}

Ecological protection education is to tell and spread knowledge information such as ecological deterioration and the disappearance of biodiversity to the public, and make the public understand, support and participate in the activities of protecting ecological environment. General science publicity has been unable to meet social needs but should be involved and substituted by protection education which has more extensive and richer contents (Zou, Jiejian, Wang, Fumin \& Deng, Yanzhong. 2009). The education of science publicity including the contents 
such as love animals and protect ecology et. al. can be carried out in the elementary and middle schools so as to improve their abilities of recognizing nature and exploring nature, advocate ecological concepts which animals are human friends and the earth is the common home of human beings and animals, and further strength the awareness of uphold science, love nature and protect ecology.

Although now the protection is strengthen the trend that the ecological environment is destroyed is out of control, whose root cause lies in lacking understandings of natural ecosystem. With the increasing progress of technology, ecology, conservation biology and other disciplines will play more roles. For example, if the establishment of ecological protection areas pay attention to the protection of rare and economic species only but ignore the protection of key species in the ecosystem, it will lead to biological invasion and species extinction et. al. The key of protecting wild animals is protecting their ecosystem they exist, not just one or two kinds of endangered species so that they will be conserved for a long time. At present, apply new spatial ecology from the aspects including population dynamics, structure and dynamics of the community, diversity and stability to make a multi-level, multidate and dynamic analysis on ecosystem. Apply Genentech to collect and protect salvageably the genetic resources materials of wild endangered species; Set up gene-polls for endangered species and provide basic data for formulating reasonably protection scheme. At the same time, investigate the living environment of endangered species and carry on unified planning and management in order to monitor the habitats macrocosmically. Plan ecological tourism zones and reserves reasonably with human activities' minimal impact on the environment and put forward effective and well-organized protection measures.

\section{References}

Chang, Hong \& Zhang, Zhongchao. (2008). The analysis on the problem of animal protection in zoos in China. Anhui agricultural science. Vol. 36, No. 24, pp. $10504-10505$.

Ding, Xinglin. (2007). A probe into the management and development of zoos in cities. Journal of Panzhihua University, Vol. 24, No. 6, pp. 93-95.

Ma, Jianzhang. (2002). China Wildlife Conservation. science and technology literature publishing house. pp. 457-520.

Zhao, Chong. (2007). Study on the current status and measures of our country's wildlife conservation. Wild Animals Protection. Vol. 6, No. 5.

Zou, Jiejian, Wang, Fumin \& Deng, Yanzhong. (2009). Several hot topics and solutions to the the work of wildlife conservation in China. Guangdong Forestry Science and Technology, Vol. 25, No. 4. 